\title{
Experimental Drugs with the Potential to Treat Atopic Eczema
}

\author{
Kam Lun Ellis Hon (iD) \\ Vivian PY Chan ${ }^{2}$ \\ Alexander KC Leung $\mathbb{D}^{3}$ \\ 'Department of Paediatrics and \\ Adolescent Medicine, The Hong Kong \\ Children's Hospital, Hong Kong, People's \\ Republic of China; ${ }^{2}$ Pharmacy \\ Department, The Hong Kong Children's \\ Hospital, Hong Kong, People's Republic \\ of China; ${ }^{3}$ Department of Pediatrics, The \\ University of Calgary, and the Alberta \\ Children's Hospital, Calgary, Alberta, \\ Canada
}

Introduction: Eczema or atopic dermatitis (AD) is a chronically relapsing dermatosis characterized by pruritus and a significant impact on the quality of life.

Methods: The authors undertook a structured search of peer-reviewed research articles from PubMed and Google Scholar. Recent and up-to-date studies relevant to the topic were included. Results: This report overviews current treatment and experimental drug for AD. Topical agents including topical phosphodiesterase E4 (PDE4) inhibitors such as crisaborole are efficacious in the treatment of AD with few side effects. Monoclonal antibodies such as dupilumab given subcutaneously are efficacious for more severe disease. Systemic treatment can ameliorate symptoms in severe and recalcitrant AD. New systemic treatment includes several traditional herbal formulations that have undergone clinical trials using modern research methodology to determine their efficacy and safety. AD is associated with many complicating psychosocial issues. Often suboptimal efficacy is due to unrealistic expectations and poor compliance making treatment difficult in spite of effective treatment and efforts in drug discovery. Randomized trials have shown that novel topical and subcutaneous medications are safe and efficacious. Regarding herbs, a methodology for the investigation of herbal medications is often flawed and scientific evidence is lacking. Experimental drugs include various biologics, PDE4 and JAK inhibitors in topical, oral, subcutaneous or intravenous forms are in various phases of trials.

Conclusion: Many novel medications demonstrate efficacy for AD. Experimental drugs include various biologics, PDE4 and JAK inhibitors are in various phases of trials.

Keywords: atopic dermatitis, biologics, crisaborole, dupilumab, eczema, JAK inhibitors

\section{Introduction}

Eczema or atopic dermatitis (AD) is a chronic relapsing allergic/inflammatory dermatitis characterized by pruritus, xerosis, erythema, vesiculation, exudation, excoriation, crusting, and sometimes lichenification. The condition can have a significant impairment of quality of life. ${ }^{1-4}$ AD is very common and affects as high as $20 \%$ of children and $1-3 \%$ of adults. ${ }^{3-10}$ According to an international survey, the prevalence of adult $\mathrm{AD}$ ranged from $2.1 \%$ to $4.9 \%$ across countries. ${ }^{11}$ The prevalence of $\mathrm{AD}$ in US adults is approximately $7 \%$, and one in four adults with $\mathrm{AD}$ report adult onset of their disease. $^{12}$

Epidemiologically, AD is prevalent among small and affluent families. ${ }^{3-10}$ Reasons for the increase in AD prevalence in the past decades are probably multifactorial.

The pathophysiology of AD is complex..$^{13-15}$ Several theories and hypotheses have been proposed. The "brick and mortar" model hypothesizes that the disease is due to an inherited defect in epidermal barrier function. ${ }^{16-19}$ Filaggrin (FLG) is a protein in the
Correspondence: Kam Lun Ellis Hon Department of Paediatrics and Adolescent Medicine, The Hong Kong Children's Hospital, Hong Kong, People's Republic of China

Tel +85235133595

Fax +85235127598

Email ehon@hotmail.com 
skin epidermal stratum corneum which is metabolized to a number of natural moisturizing factors (NMF) that contribute to the cutaneous barrier integrity. ${ }^{16-21}$ The cytoskeleton with filaggrin forms a protein-lipid matrix, which impedes the entry of chemicals, infectious agents and allergens, and prevents transepidermal water loss (TEWL). ${ }^{20,21}$ Downregulation or loss-of-function mutation in the filaggrin gene sensitizes these individuals to develop atopic skin. ${ }^{17,22-26}$ The hygiene hypothesis suggests that immune dysregulation during early childhood increases the risk for allergy. ${ }^{27,28}$ The hypothesis states that early childhood exposure to several microorganisms in the gut flora protects against atopic diseases. ${ }^{29,30}$ A lack of exposure to the normal gut flora is thought to lead to problems in establishing immune tolerance. $^{29}$ Dysbiosis is another theory that further postulates overuse of antibiotics and changes in life style leads to an overgrowth of staphylococcus and various microbials as pathophysiological mechanisms in AD. ${ }^{3-5,31-34}$ According to the $T$ Helper $\left(T_{H}\right)$ hypothesis, an imbalance of T-helper cell immunology is associated with $\mathrm{AD}$ pathogenesis. Children with $\mathrm{AD}$ have a high concentration of various $\mathrm{T}_{\mathrm{H}}$ cytokines and chemokines, such as $\mathrm{T}_{\mathrm{H}} 17$ IL-31 and IL-33 and antimicrobial peptides in the skin. ${ }^{35,36}$ The interplay of these theories and hypotheses points to a complex mechanism of AD pathogenesis that cannot be explained by any sole theory or hypothesis alone. ${ }^{3-5,37}$ Successful management of this disease demands a multipronged approach consisting of optimal skincare and pharmacotherapy. ${ }^{1,3-5}$ To complicate matters, there are several cultural and psychosocial issues that make AD difficult to manage in some countries. ${ }^{38}$

We undertook a structured search of peer-reviewed research articles from PubMed and Google Scholar. Recent and up-to-date studies relevant to the topic were included. The Pubmed search was conducted in Clinical Queries using the key term "atopic dermatitis" and "eczema". The search included meta-analyses, randomized controlled trials, clinical trials, observational studies, and reviews. The search was restricted to English literature. The information retrieved from the above search was used in the compilation of the present article.

\section{Overview of Therapies for Atopic Dermatitis}

\section{Emollients and Moisturizers}

Many guidelines and practical recommendations have been developed for the management of AD. ${ }^{5,39-41}$
Emollients and moisturizers are integral parts of AD management but are often not considered as topical medications. There have been a proliferation of emollients and moisturizers in recent years. These emollients contain NMF and/or pseudoceramides that claim good barrier repair functions. They are marketed as proprietary products. $^{42-47}$ Key players in the skin barrier are the natural NMF and ceramides. ${ }^{48,49}$ Few of these products have been subjected to trials to establish their efficacy. ${ }^{43,45,48,50}$ A Cochrane review on emollient trials demonstrates that many moisturizers have some beneficial effects but none is superior to another. ${ }^{51}$

\section{Corticosteroids}

Conventionally, topical corticosteroids (TCS) marked the beginning of modern therapeutics for the management of $\mathrm{AD}$ and is the mainstay of treatment. ${ }^{1,3}$ The risk of side effects depends on the area being covered, strength of the medication, and the duration of treatment, with children being more prone to their adverse effects following inadvertent usage. ${ }^{1,52}$ Chronic use of topical steroids may be problematic, especially in young children, due to potential adrenal axis suppression and the risk of growth retardation, as well as local steroid side effects, such as skin thinning and depigmentation. Described as steroid phobia, many parents are reluctant to use steroids on their children. $^{38,53,54}$

\section{Topical Immunomodulators}

Topical calcineurin inhibitors (TCI) are useful and safe topical medications as an alternative to corticosteroids. Tacrolimus (Protopic) and pimecrolimus (Elidel) are the two commercially available TCIs. These immunomodulators down-regulate inflammation, inhibit the activity of calcineurin and block the activation of $\mathrm{T}$ and natural killer cells. Both immunomodulators are efficacious and safe. ${ }^{1}$ Generally, TCIs are less effective and cause more skin burning and irritating sensation than topical corticosteroids. In February 2005, the Pediatric Advisory Committee of the Food and Drug Administration (FDA) recommended that "black box warnings" be placed on tacrolimus and pimecrolimus because of the potential risk of cancer. ${ }^{55}$ In March 2005, the FDA issued an alert to health-care providers concerning a potential link between these topical calcineurin inhibitors and malignancy (skin cancer and lymphoma). ${ }^{55}$ Subsequently, a Joint Task Force of the American College of Allergy, Asthma, and Immunology and the American Academy of 
Allergy, Asthma and Immunology concluded that the current data did not support the use of "black box warning" on these medications. ${ }^{55}$

\section{Systemic Medications}

Most guidelines recommend systemic medications in the management of severe and recalcitrant AD. ${ }^{1,456,57}$ These medications may be associated with significant systemic side effects. ${ }^{4,56,57}$ In particular, azathioprine is associated with neutropenia and impaired hepatic function whereas cyclosporin is associated with hypertension and impairment of renal function. ${ }^{3-5,56,58,59}$ These medications are therefore not accepted by parents and patients for longterm disease control. ${ }^{59}$ Furthermore, current international guidelines place limits on the prolonged use of cyclosporine. Methotrexate is another widely used drug, especially in adults. However, in many countries, cyclosporine is the only licensed traditional systemic drug for $\mathrm{AD} .{ }^{39,40}$

\section{Novel Treatments}

Novel therapeutic agents targeting the complex pathophysiology have been developed. The new drugs are efficacious and with less side effect compared to conventional medications. The move towards personalized medicine appears to be the way forward in drug development programs in AD. ${ }^{60-64}$ Many topical and systemic drugs were initially developed as experimental agents but have been subsequently successfully marketed. They include systemic Janus kinase (JAK) inhibitors, subcutaneous monoclonal antibodies and topical PDE4 inhibitors. ${ }^{44}$

Among these successfully launched products, the biologics drug class leads the marketand has dominated the global drugs market for the treatment of AD since 2018.

Dupilamab (Dupixent) is a fully human monoclonal antibody that has been approved as an IL-4Ra targeting biologic and an IL-4/IL-13 inhibitor, which is administered subcutaneously for the treatment of moderately severe AD. ${ }^{65-68}$ In Phase II and III randomized trials conducted on adult patients, dupilumab reduced the $\mathrm{AD}$ severity. ${ }^{67-72}$ Dupilumab has been approved by the FDA for the treatment of severe $\mathrm{AD}$ and successfully marketed. ${ }^{73}$ The drug is an immunoglobulin G4 antibody that inhibits interleukin-4 (IL-4) and IL-13 signaling by specifically binding to the IL-4 receptor alpha subunit, which is shared by the IL-4 and IL-13 receptor complexes. ${ }^{74}$ IL-4 and IL13 are initiators and drivers of the helper T-cell type 2 (TH2) axis. ${ }^{75}$ In two Phase III trials, dupilumab improved signs and symptoms and the quality of life of $\mathrm{AD}$ patients. The drug has an acceptable safety profile. The most common adverse effects are nasopharyngitis, upper respiratory tract infections, injection site reactions and conjunctivitis. ${ }^{75}$ Real-life experiences in adults and in the elderly have now been reported. ${ }^{76,77}$

Topical therapy is an integral part of AD care. ${ }^{75}$ For decades, the two primary classes of topical drugs used to treat $\mathrm{AD}$ include topical corticosteroids and calcineurin inhibitors. Overactive phosphodiesterase (PDE)-4 enzyme contributes to the signs and symptoms of $\mathrm{AD}^{75}$ Crisaborole is a PDE4 antagonist that inhibits the degradation of cyclic adenosine monophosphate (cAMP) by PDE4, and results in downstream modification of proinflammatory signaling pathways. ${ }^{75}$ Crisaborole has demonstrated significant efficacy in a phase III clinical trial. ${ }^{78}$ A Phase I, randomized, double-blind trial has also shown that the application of topical crisaborole to sensitive skin areas of healthy volunteers was well tolerated throughout treatment, thus supporting its potential role as an alternative topical treatment in AD patients. ${ }^{79}$ However, crisaborole's affinity for the 4 different PDE-4 isotypes is weak potentially explaining its modest efficacy in $\mathrm{AD}$. Furthermore, it burns/stings at the site of application. On top of this, crisaborole is an ointment (which patients prefer less than creams) that requires twice daily application. ${ }^{80}$ On the other hand, the drug does not cause thinning of the skin. In patients with mild-to-moderate $\mathrm{AD}$, Crisaborole interrupts the itch-scratch cycle and helps improve quality of life within a short duration of treatment. ${ }^{78,81-85}$ The US FDA has now approved the usage of crisaborole for children $\geq 2$ years with mild to moderate $\mathrm{AD} .^{44,75,80,81,84}$ Real-life experiences of crisaborole have been reported. ${ }^{86}$ In summary, subcutaneous dupilumab and topical crisaborole are now available in the market. They are expensive drugs but have good safety profiles.

\section{Miscellaneous}

The development of new moisturizers containing pseudoceramides and natural moisturizing factors generally lacks efficacy data. ${ }^{38}$ Bleach bathing has been recommended as an adjuvant treatment for $\mathrm{AD} .{ }^{87}$ Bathing with water alone might be similarly useful. ${ }^{88}$ Sodium hypochlorite bathing has not acquired popularity in Europe. ${ }^{88,89,90}$ Recently, bathing with pine-tar has been demonstrated as a useful adjuvant practice for $\mathrm{AD}$ patients. Clinical improvement is associated with the reduction of $\operatorname{IgE}$ and skin S. aureus. ${ }^{91,92}$ 
In parallel to western medicine, traditional Chinese medicine, naturopathy, homeopathy, and many folklore treatments have been widely accepted by patients but many lack scientific evidence and have not been extensively studied. ${ }^{93-96}$ Mismatch between parental expectations and treatment outcomes can hinder compliance and lead to treatment failure. ${ }^{94,96-100}$ Research has failed to demonstrate that alternative therapies are consistently effective. ${ }^{93,95}$

Chinese herbs have been used to treat AD for many generations. ${ }^{94,96,101-104}$ The efficacy of various forms of oral Chinese medicine in childhood $\mathrm{AD}$ has not been consistently shown. ${ }^{105-109}$ Systematic reviews and metaanalyses have been performed which consistently demonstrated no conclusive evidence that most Chinese herbal concoctions could improve AD. ${ }^{110-114}$ Generally, strength of evidence is low and the risks of bias are high in these studies. Mechanisms of action of herbal medicine have been reported. ${ }^{44,93,111-113,115}$

In the early 1990s, a decoction was reported to be useful for treating $\mathrm{AD}$ but a subsequent randomized trial involving the same decoction did not show any effects. ${ }^{108,116-119}$ In Hong Kong, a series of trials on a herbal concoction for pediatric patients $\mathrm{AD}$ has demonstrated efficacy and improvement of quality of life. ${ }^{120-128}$ The concoction is now commercially available.

In $\mathrm{AD}$, the symptom of sleep disturbance and itch is prevalent due to reduced nocturnal melatonin secretion. ${ }^{3-5}$ Oral melatonin is a safe and effective treatment to improve disease severity due to its antioxidative and immunomodulatory effects. ${ }^{129}$ In a randomized trial, AD severity and sleep-onset latency were improved with melatonin. ${ }^{129}$

Naturopathy, homeopathy and osteopathy are several modalities of Complementary and Alternative Medicine (CAM) claiming their usefulness for the treatment of AD. ${ }^{93,126,130-132}$ However, there is insufficient evidence of their efficacy. Alternatively, several Chinese herbal formulae have been used topically and orally in $\mathrm{AD} .{ }^{96,110,112}$ To date, there has been evidence that an oral Chinese herbal concoction ameliorates $\mathrm{AD}$ in pediatric patients. ${ }^{96}$ Toxicity associated with herbs must simultaneously be investigated in clinical trials. Most importantly, control of herbal medicinals to be investigated and their quality assurance must be performed in double-blind, placebocontrolled clinical trials. ${ }^{125,126}$ Well-designed, adequately powered clinical trials are mandatory to evaluate the efficacy and safety profile of herbal medicinals in the management of $\mathrm{AD} .^{110,113}$

\section{Experimental Drugs for Atopic Dermatitis}

Experimental drugs that are being investigated include topical, subcutaneous and oral forms of medications.

\section{Topical Agents}

Among the topical agents, a moisturizing cream containing Rhamnosoft, L-isoleucine (ILE) and ceramides has been developed for treating facial AD. ${ }^{132}$ Topical ceramides in this pro-AMP cream restore the skin barrier, whereas topical L-isoleucine potentiates cutaneous $\beta$-defensin and stimulates AMP production. In a randomized, controlled trial, the pro-AMP cream was efficacious for children with mild-to-moderate chronic facial $\mathrm{AD} .^{50,132}$

A selective PDE4 inhibitor (OPA-15,406) ointment has been demonstrated to be efficacious in the treatment of AD. Adverse events are uncommon and usually mild. $^{13,44}$

Other topical agents for the treatment of AD are the JAK inhibitors. ${ }^{75}$ Several proinflammatory cytokines elicit their actions on the intracellular signaling pathway [JAKsignal transducer and activator of transcription (JAKSTAT)]. These agents work by inhibiting the activity of the JAK family of enzymes (JAK1, JAK2, JAK3, TYK2), thereby phosphorylating activated cytokine receptors. These phosphorylated receptors in turn activates the JAKsignal transducer and activator of transcription (STAT) transcription factors which modulate gene transcription. ${ }^{75}$ Topical JAK inhibitor decreases IL-4 and IL-13 signaling and improves the barrier function of the skin.

Tofacitinib is a small-molecule JAK inhibitor approved for the treatment of rheumatoid arthritis that blocks multiple cytokine signaling, including interleukin IL-4. IL-5 and IL-13 implicated in immune response and inflammation. ${ }^{14}$ Topical tofacitinib has shown efficacy in a phase IIa, randomized, double-blind controlled study with 69 adults with mild to moderate $\mathrm{AD} .{ }^{15}$ In another phase IIa trial, topical tofacitinib also demonstrated efficacy. ${ }^{15,44}$ Further research is needed. Adverse effects, including infection, increased blood creatine phosphokinase and contact dermatitis, were mild in patients receiving tofacitinib. ${ }^{15}$

Histamine is a pruritogen. $\mathrm{H}_{1}$ and $\mathrm{H}_{2}$ receptor antagonists have shown poor efficacy in reducing pruritis associated with AD. ${ }^{91,92}$ Nevertheless, a recent meta-analysis of three studies showed that topical $4 \%$ sodium cromoglycate emulsion was effective in the management of $\mathrm{AD}$ in the pediatric 
age group. ${ }^{44,93}$ Meanwhile, $\mathrm{H}_{4}$ receptor antagonist has recently been developed which may reduce histamineinduced itch and eczema severity. ${ }^{94,95,115,133,134}$

Another systematic review of three databases on topical treatment with silver-coated fabrics or engineered silk concluded that recommendation for the functional textiles usage in $\mathrm{AD}$ is weak. ${ }^{36}$

As the therapeutic pipeline for AD is growing, several agents are coming closer to market. Two promising topical agents are tapinarof and roflumilast.

Tapinarof influences both Th17 and Th2 pathways, it has the potential to impact the pathways in both psoriasis and $\mathrm{AD}$. It is believed that the aryl hydrocarbon receptor (AhR) modulation by tapinarof increases antioxidant activity via upregulation of NF-E2-related factor 2 (Nrf2) and promotes skin barrier restoration through upregulation of a number of epidermal barrier genes, including filaggrin, hornerin, and involucrin. Tapinarof, a Therapeutic Aryl hydrocarbon receptor Modulating Agent (TAMA), inhibits the IL-17A and IL-17F pathways implicated in psoriasis and IL-4, IL-5, and IL-13 in $\mathrm{AD}$. It is a natural AhR agonist that resolves skin inflammation in mice and humans. ${ }^{135}$ Tapinarof $1 \%$ cream applied once a day demonstrated statistically significant improvement in EASI75 and BSA compared to vehicle applied once a day at week $12 .{ }^{136}$ Commonly reported adverse events include nasopharyngitis and folliculitis. $^{136}$

ARQ-151 is a once-daily topical cream formulation of roflumilast. Roflumilast is a highly potent and selective PDE4 inhibitor that is under development for $\mathrm{AD}$ and psoriasis. The topical cream is used once daily and has shown greater potency (25-to 300-fold) than the two other FDA-approved PDE4 inhibitors for psoriasis. ${ }^{137,138}$ In

a Phase II proof-of-concept study, it was reported that roflumilast cream was well tolerated for psoriasis. ${ }^{137}$ However, trial on the use of roflumilast for the treatment of AD has not materialized. ${ }^{139}$ The safety and tolerability of ARQ-151 in AD is particularly important given that most $\mathrm{AD}$ subjects are young children. Also, because $\mathrm{AD}$ is a skin barrier defect, there is an increased risk of systemic exposure, even with topical treatment. ${ }^{97}$

\section{Subcutaneous Agents}

IL-31 is an important interleukin in $\mathrm{AD}$ pathogenesis. Safety and efficacy of nemolizumab (CIM331) in AD have been shown in a randomized clinical trial. ${ }^{98}$ Nemolizumab is a subcutaneously administered humanized monoclonal antibody against IL-31 receptor A, IL-31 is a newly discovered cytokine that is involved in pruritus and inflammation in AD. ${ }^{14}$ It has been shown that subcutaneous nemolizumab significantly improves pruritus in patients with moderate-to-severe AD. In a phase II clinical trial, monthly injections of nemolizumab significantly inhibited pruritus in patients with moderate to severe AD. ${ }^{98}$ Nemolizumab also decreased the use of topical corticosteroid and ameliorated sleep efficiency in that trial. ${ }^{98}$ The efficacy of nemolizumab in reducing pruritus was also evaluated in a 16 week, double-blind, phase III trial of 215 Japanese patients aged 13 years and older with $\mathrm{AD}$ who had moderate-to-severe pruritus. ${ }^{99}$ Patients were randomized to receive subcutaneous nemolizumab (60 $\mathrm{mg}$ ) or placebo every 4 weeks until week 16, with concomitant topical agents. ${ }^{99}$ The mean percent change in the visual-analogue scale (VAS) score for pruritus was reduced by $42.8 \%$ in the nemolizumab group compared to $21.4 \%$ in the placebo group. ${ }^{99}$ The incidence of injection site reactions was greater with nemolizumab than placebo. The authors suggested that longer and larger trials are necessary to determine whether nemolizumab has a durable effect and is safe for the treatment of AD. ${ }^{99}$

Lebrikizumab is a high-affinity, monoclonal antibody that binds specifically to the soluble IL-13 and prevents the formation of the IL-13Ra1/IL-4Ra heterodimer receptor signaling complex. ${ }^{100}$ Lebrikizumab has also previously been investigated for the treatment of asthma with inconsistent results. ${ }^{140-142}$ Lebrikizumab was studied in a proof-of-concept, randomized double-blind phase II trial of 209 adult patients with moderate to severe AD in combination with mandatory topical corticosteroids. ${ }^{143}$ At week 12, significantly more patients achieved EASI-50 (reduction of Eczema Area and Severity Index by $50 \%)^{144}$ with subcutaneous lebrikizumab $125 \mathrm{mg}$ every 4 weeks than placebo $(82.4 \%$ vs $62.3 \%)$. However, the protocol-mandated topical corticosteroids have limited the understanding of the efficacy of lebrikizumab as monotherapy and the short study duration did not enable longterm safety or efficacy evaluation. ${ }^{143}$

In a phase IIb double-blind, randomized, placebocontrolled trial, adults with moderate-to-severe AD were treated with dose-ranging lebrikizumab injections every 4 weeks or every 2 weeks. At week 16, the lebrikizumab groups showed dose-dependent, statistically significant improvement in Eczema Area and Severity Index (EASI) scores compared to the placebo group. ${ }^{75,100}$ Common 
adverse effects in the lebrikizumab groups included upper respiratory tract infection, nasopharyngitis, headache, pain at the injection site and fatigue. ${ }^{14}$

Tralokinumab for atopic dermatitis is another promising new therapy. ${ }^{145}$ In a Phase $2 b$, randomized, doubleblind, placebo-controlled, dose-ranging study in adults with moderate-to-severe $\mathrm{AD}$, patients received subcutaneous tralokinumab or placebo every 2 weeks for 12 weeks and topical corticosteroid cream or ointment at least once daily from the run-in to end of follow-up. Tralokinumab improved health-related QoL in patients with moderate-to-severe $\mathrm{AD}$, providing further evidence of the value of targeting interleukin-13 in such patients. ${ }^{146}$

\section{Oral Agents}

Among the oral agents, apremilast is an oral PDE-4 inhibitor proven effective for the treatment of psoriasis vulgaris and psoriatic arthritis. Apremilast has shown some efficacy in $\mathrm{AD} .{ }^{44,147}$

A number of oral JAK inhibitors are being investigated for the treatment of $\mathrm{AD} .{ }^{15,44} \mathrm{JAK}$ inhibitors are small molecules that exert their immunosuppressive and antiproliferative effects by inhibiting the JAK-STAT. ${ }^{148}$ Current agents under investigation for use in AD include baricitinib (a JAK1 and JAK2 inhibitor), upadacitinib (JAK1 inhibitor) and abrocitinib (JAK1 inhibitor). The efficacy of oral baricitinib was evaluated in a phase II doubleblinded trial of 124 adults with moderate-to-severe AD. Significantly more patients who received baricitinib ( $4 \mathrm{mg}$ ) achieved EASI-50 than patients receiving placebo (61\% vs $37 \%$ ) at 16 weeks. ${ }^{149}$ Adverse effects relating to baricitinib included headache, increased blood levels of creatine phosphokinase, decrease in the neutrophil count and nasopharyngitis. ${ }^{149}$

The efficacy and safety of oral abrocitinib monotherapy has also been evaluated in a phase II and phase III trial and were found to be effective and well tolerated for shortterm use in adults with moderate to severe AD. ${ }^{150,151}$ It is an investigational oral once-daily JAK1 inhibitor. A phase III randomized placebo-controlled trial (JADEMONO-1) to assess the efficacy of oral once-daily abrocitinib showed improvements in pruritis and disease burden at week 2 of treatment and continued throughout the rest of the 12week study. ${ }^{150}$

Upadacitinib also shows promising results in a phase II clinical for $\mathrm{AD}$. In that study, $50 \%$ of the participants treated with $30 \mathrm{mg}$ daily of upadacitinib, achieved EASI-
90 response at week $16 .^{75,148}$ However, ongoing studies are required to evaluate its safety profile. ${ }^{99}$

Along another line for oral agents for the management of $\mathrm{AD}$ is fecal transplants with commensal bacteria. ${ }^{152} \mathrm{In}$ a randomized double-blind trial, lysate of Vitroscilla filiformis bacterium reduced cutaneous S. aureus colonization, severity and pruritus of AD. ${ }^{155}$ This implies the use of commensal strains to control biofilm formation and overgrowth of pathogenic staphylococci. ${ }^{156,157}$ Transplantation of cutaneous commensal gram-negative rods from healthy individuals activates innate immunity and controls the growth of $S$. aureus in a mouse model. ${ }^{158}$ When applied to human eczematous skin, Staphylococcus hominis and S. epidermidis from healthy non-atopic individuals decrease $S$ aureus colonization. ${ }^{159}$ Studies of the topical application of gram-negative coccobacillus commensal and coagulase-negative Staphylococcus for AD are ongoing. ${ }^{159160161}$

\section{Intravenous Agents}

IL-22 induces epidermal hyperplasia and plays a major role in barrier function disruption in model systems. ${ }^{154}$ A randomized double-blind, placebo-controlled trial evaluated the efficacy and safety of intravenous fezakinumab, an anti-IL22 antibody, as monotherapy in adult patients with moderate to severe AD. At week 12, there was no significant decline in Scoring AD (SCORAD). Significant findings were only demonstrated in the subset of patients with severe $\mathrm{AD} .{ }^{14}$ The drug was well tolerated and the common adverse events were upper respiratory infections.

\section{Miscellaneous}

Transient receptor potential (TRP) ion channels are involved in the transmission of somatosensory signaling, such as heat, pain and taste throughout the body. ${ }^{153}$ TRP cation channel subfamily V member 1 or TRPV1, one of the members of this large family of ion channel, is expressed on diverse cells of this skin and is an important molecule in pruritus signaling in AD. ${ }^{154}$ TRPVI also appears to play a role in maintaining skin barrier function. Neurokinin antagonists may also affect similar pathway of pruritus signaling by blocking the substance $P$ neuropeptide that mediates pruritus and affect neurogenic inflammation. Several trials that are undergoing evaluation of the efficacy and safety of this class of drugs include PAC-14,028 (TRPV1 channel inhibitor), CT327/SNA120 (TrkA kinase inhibitor), tradipitant 
(Neurokini 1/SP antagonist) and serlopitant VPD-737 (Neurokinin antagonist). ${ }^{154}$

Given the role of prostaglandins and leukotrienes plays in the development of atopy in asthma pathogenesis, in vitro and in vivo studies of $\mathrm{AD}$ have suggested that these molecules may be important in the pathogenesis of $\mathrm{AD}^{89}$ Therefore, targeted therapy against these molecules may have a role in the management of AD. Several agents in development that targets the leukotriene/prostaglandin pathway include C000459, Q301 and ZPL-521. ${ }^{89}$

Two anti-alarmin drugs were investigated for $\mathrm{AD}$, namely etokinumab and tezepelumab. The role of IL-33 inhibition was investigated in a phase 2a study of etokimab, an IgG1 anti-IL-33 monoclonal antibody, in 12 adult patients with moderate-to-severe $\mathrm{AD}$ who received a single intravenous administration of etokimab. ${ }^{162}$ A sustained clinical benefit was observed with $83 \%$ achieving EASI-50 and 33\% EASI-75, and with a reduction in peripheral eosinophils at day 29 after administration. Etokimab also inhibited neutrophil migration to skin interstitial fluid in vitro.

The role of an anti-thymic stromal lymphopoietin monoclonal antibody was investigated in a phase $2 \mathrm{a}$ study (NCT02525094) where adult patients were randomized to subcutaneous tezepelumab $280 \mathrm{mg}$ or placebo every 2 weeks, plus class 3 topical corticosteroids (TCS). ${ }^{90,163}$ The primary endpoint was the week 12 response rate in the EASI-50. Although not statistically significant, numerical improvements over placebo were demonstrated.

Alefacept (intravenous/intramuscular) and efalizumab (subcutaneous) are other biologics effective in the treatment of moderate to severe AD in adults but long-term administration of these agents are limited by their significant toxicity. ${ }^{152}$ They are not currently marketed.

\section{Conclusions}

This review summarizes AD medications in topical, subcutaneous and oral forms and explores novel and investigational drugs. Some have been successfully marketed whilst others remain experimental. PDE4 inhibitors are an effective topical treatment for mild-to-moderate $\mathrm{AD}$ whereas dupilumab is an effective subcutaneous agent for the treatment of moderate-to-severe $\mathrm{AD}$ with little minimal effects.

Experimental treatments in topical, subcutaneous and oral forms are ongoing and include antihistamine and biologics. The usage of biologics is a major advance in the management of AD. Dupilumab is now available in the market. The drug has been subjected to extensive randomized controlled trials and confirmed to be useful and safe. The efficacy profile of crisaborole is comparable to topical steroid and calcineurin inhibitors but is a lot more expensive. Nevertheless, longer term follow-up studies are needed to evaluate potential adverse events. One disadvantage of using dupilumab is that the medication has to be administered subcutaneously twice weekly and is painful for children. Furthermore, dupilumab is a very costly medication.

Currently, the majority of novel and experimental medications have been developed and marketed for adults with AD. Only subcutaneous Dupilumet and topical Crisaborole have been successfully marketed for patients younger than 18 years of age.

There has been an exploding proliferation of many new antibodies, biologics and small molecules that are undergoing Phase II and III clinical trials. Eventually, some of these medications may be successfully marketed. However, it appears that there remains no cure for $\mathrm{AD}$ to date.

\section{Disclosure}

The authors declare that they have not received any funding supports for this review, have no conflicts of interest, and have received no payment for the preparation of this manuscript.

\section{References}

1. Leung AKC, Hon KL. Atopic Dermatitis: A Review for the Primary Care Physician. Atopic Dermatitis: A Review for the Primary Care Physician. Vol. c2011. Hauppauge, N.Y.: Nova Science Publishers; 2011:1-113.

2. Hon KL, Lam MC, Leung TF, Chow CM, Wong E, Leung AKC. Assessing itch in children with atopic dermatitis treated with tacrolimus: objective versus subjective assessment. Adv Ther. 2007;24 (1):23-28. doi:10.1007/BF02849989

3. Leung AKC, Hon KL, Robson WL. Atopic dermatitis. Adv Pediatr. 2007;54(1):241-273. doi:10.1016/j.yapd.2007.03.013

4. Leung TNH, Chow CM, Chow MP, et al. Clinical guidelines on management of atopic dermatitis in children LEUNG2013. Hong Kong J Paediatr. 2013;18(2):96-104.

5. Leung TN, Hon KL. Eczema therapeutics in children: what do the clinical trials say? Hong Kong Med J. 2015;21(3):10.

6. Abramovits W, Simpson EL, Hanifin JM. Atopic dermatitis. J Am Acad Dermatol. 2005;53(1):S86-93. doi:10.1016/j.jaad.2005.04.034

7. Leung R, Wong G, Lau J, et al. Prevalence of asthma and allergy in Hong Kong schoolchildren: an ISAAC study. Eur. 1997;10 (2):354-360.

8. Leung DY, Nicklas RA, Li JT, et al. Disease management of atopic dermatitis: an updated practice parameter. Joint task force on practice parameters. Ann Allergy Asthma Immunol. 2004;93(3Suppl 2):S1-S21. doi:10.1016/S1081-1206(10)61385-3 
9. Simpson EL. Atopic dermatitis: a review of topical treatment options. [Review] [47 refs]. Curr Med Res Opin. 2010;26 (3):633-640. doi:10.1185/03007990903512156

10. Shaw TE, Currie GP, Koudelka CW, Simpson EL. Eczema prevalence in the United States: data from the 2003 national survey of children's health. J Invest Dermatol. 2011;131(1):67-73. doi:10.1038/jid.2010.251

11. Barbarot S, Auziere S, Gadkari A, et al. Epidemiology of atopic dermatitis in adults: results from an international survey. Allergy Eur J Allergy Clin Immunol. 2018;73(6):1284-1293. doi:10.1111/all.13401

12. Vakharia PP, Silverberg JI. Adult-onset atopic dermatitis: characteristics and management. Am J Clin Dermatol. 2019;20:771-779. doi:10.1007/s40257-019-00453-7

13. Hanifin JM, Ellis CN, Frieden IJ, et al. OPA-15406, a novel, topical, nonsteroidal, selective phosphodiesterase-4 (PDE4) inhibitor, in the treatment of adult and adolescent patients with mild to moderate atopic dermatitis (AD): a phase-II randomized, double-blind, placebo-controlled study. $J$ Am Acad Dermatol. 2016;75(2):297-305. doi:10.1016/j.jaad.2016.04.001

14. Papp KA, Bissonnette R, Gooderham M, et al. Treatment of plaque psoriasis with an ointment formulation of the Janus kinase inhibitor, tofacitinib: a Phase $2 \mathrm{~b}$ randomized clinical trial. $B M C$ Dermatol. 2016;16(1). doi:10.1186/s12895-016-0051-4

15. Bissonnette R, Papp KA, Poulin Y, et al. Topical tofacitinib for atopic dermatitis: a phase IIa randomized trial. $\mathrm{Br} J$ Dermatol. 2016;175(5):902-911. doi:10.1111/bjd.14871

16. Cork MJ, Danby SG, Vasilopoulos Y, et al. Epidermal barrier dysfunction in atopic dermatitis.. J Invest Dermatol. 2009;129 (8):1892-1908. doi:10.1038/jid.2009.133

17. Jungersted JM, Scheer H, Mempel M, et al. Stratum corneum lipids, skin barrier function and filaggrin mutations in patients with atopic eczema. Allergy. 2010;65(7):911-918. doi:10.1111/ j.1398-9995.2010.02326.x

18. Weidinger S, Illig $\mathrm{T}$, Baurecht $\mathrm{H}$, et al. Loss-of-function variations within the filaggrin gene predispose for atopic dermatitis with allergic sensitizations.[erratum appears in $\mathrm{J}$ Allergy Clin Immunol. 2006 Oct;118(4):922]. J Allergy Clin Immunol. 2006;118(1):214-219. doi:10.1016/j.jaci.2006.05.004

19. Nemoto-Hasebe I, Akiyama M, Nomura T, Sandilands A, McLean WH, Shimizu H. Clinical severity correlates with impaired barrier in filaggrin-related eczema. J Invest Dermatol. 2009;129(3):682-689. doi:10.1038/jid.2008.280

20. Enomoto H, Hirata K, Otsuka $\mathrm{K}$, et al. Filaggrin null mutations are associated with atopic dermatitis and elevated levels of $\operatorname{IgE}$ in the Japanese population: a family and case-control study. J Hum Genet. 2008;53(7):615-621. doi:10.1007/s10038-008-0293-Z

21. Candi E, Schmidt R, Melino G. The cornified envelope: a model of cell death in the skin.. Nat Rev Mol Cell Biol. 2005;6 (4):328-340. doi:10.1038/nrm 1619

22. Marenholz I, Nickel R, Ruschendorf F, et al. Filaggrin loss-offunction mutations predispose to phenotypes involved in the atopic march. J Allergy Clin Immunol. 2006;118(4):866-871. doi:10.1016/j.jaci.2006.07.026

23. Palmer CN, Irvine AD, Terron-Kwiatkowski A, et al. Common loss-of-function variants of the epidermal barrier protein filaggrin are a major predisposing factor for atopic dermatitis.[see comment]. Nat Genet. 2006;38(4):441-446. doi:10.1038/ng1767

24. Sandilands A, Terron-Kwiatkowski A, $\operatorname{Pr} H$, et al. Comprehensive analysis of the gene encoding filaggrin uncovers prevalent and rare mutations in ichthyosis vulgaris and atopic eczema. Nat Genet. 2007;39(5):650-654. doi: $10.1038 / \mathrm{ng} 2020$

25. Ching GK, Hon KL, Ng PC, Leung TF. Filaggrin null mutations in childhood atopic dermatitis among the Chinese. Int J Immunogenet. 2009;36(4):251-254. doi:10.1111/j.1744313X.2009.00859.x
26. Krakowski AC, Eichenfield LF, Dohil MA. Management of atopic dermatitis in the pediatric population. Pediatr. 2008;122 (4):812-824. doi:10.1542/peds.2007-2232

27. Bufford JD, Gern JE. The hygiene hypothesis revisited. Immunol Allergy Clin North Am. 2005;25(2):247-2vi. doi:10.1016/j. iac. 2005.03.005

28. Flohr C, Yeo L. Atopic dermatitis and the hygiene hypothesis revisited. Curr Probl Dermatol. 2011;41(1-34):d:1-34.

29. Scudellari M. Cleaning up the hygiene hypothesis. Proc Natl Acad Sci USA. 2017;114:1433-1436. doi:10.1073/pnas.1700 688114

30. Stiemsma L, Reynolds L, Turvey S, Finlay B. The hygiene hypothesis: current perspectives and future therapies. ImmunoTargets Ther. 2015;4:143. doi:10.2147/ITT.S61528

31. Chua HH, Chou HC, Tung YL, et al. Intestinal dysbiosis featuring abundance of ruminococcus gnavus associates with allergic diseases ininfants. Gastroenterol. 2017;11(17):10.

32. Tang MF, Sy HY, Kwok JS, et al. Eczema susceptibility and composition of faecal microbiota at four weeks of age: a pilot study in Chinese infants. Br J Dermatol. 2016;174(4):898-900. doi:10.1111/bjd.14205

33. Hon KL, Lam MC, Leung TF, et al. Clinical features associated with nasal Staphylococcus aureus colonisation in Chinese children with moderate-to-severe atopic dermatitis. Ann Acad Med Singap. 2005;34(10):602-605.

34. Hon KL, Tsang KY, Kung JS, Leung TF, Lam CW, Wong CK. Clinical signs, Staphylococcus and atopic eczema-related seromarkers. Mol. 2017;22(2):E291. doi:10.3390/ molecules22020291

35. Stevens MT, Edwards AM. The effect of 4\% sodium cromoglicate cutaneous emulsion compared to vehicle in atopic dermatitis in children-a meta-analysis of total SCORAD scores. J Dermatol Treat. 2014;26(3):1-7.

36. Lopes C, Silva D, Delgado L, Correia O, Moreira A. Functional textiles for atopic dermatitis: a systematic review and meta-analysis. Pediatr Allergy Immunol. 2013;24(6):603-613. doi:10.1111/pai.12111

37. Hon KL, Wang SS, Pong NH, Leung TF. Circulating immunoglobulins, leucocytes and complements in childhood-onset atopic eczema. Indian J Pediatr. 2012;80(2):128-131.

38. Hon KL, Leong KF, Leung TN, Leung AK. Dismissing the fallacies of childhood eczema management: case scenarios and an overview of best practices. Drugs Context. 2018;7:1-12. doi: $10.7573 /$ dic. 212547

39. Wollenberg A, Barbarot S, Bieber T, et al. Consensus-based European guidelines for treatment of atopic eczema (atopic dermatitis) in adults and children: part II. J Eur Acad Dermatol Venereol. 2018;32(6):850-878.

40. Wollenberg A, Barbarot S, Bieber T, et al. Consensus-based European guidelines for treatment of atopic eczema (atopic dermatitis) in adults and children: part I. J Eur Acad Dermatol Venereol. 2018;32(5):657-682.

41. Luk D, Kle H, Mvc D, et al. Practical recommendations for the topical treatment of atopic dermatitis in South and East Asia. Dermatol Ther (Heidelb). 2020;11(1). doi:10.1007/s13555-02000467-8

42. Hon KL, Kung JSC, Ng WGG, Leung TF. Emollient treatment of atopic dermatitis: latest evidence and clinical considerations. Drugs Context. 2018;7:212530. doi:10.7573/dic.212530

43. Hon KL, Tsang YC, Pong NH, et al. Patient acceptability, efficacy, and skin biophysiology of a cream and cleanser containing lipid complex with shea butter extract versus a ceramide product for eczema. Hong Kong Med J. 2015;21(5):417-425.

44. Hon KL, Leung AKC, Leung TNH, Lee VWY. Investigational drugs for atopic dermatitis. Expert Opin Investig Drugs. 2018;27 (8):637-647. doi:10.1080/13543784.2018.1494723 
45. Hon KL, Leung AKC, Barankin B. Barrier repair therapy in atopic dermatitis: an overview. Am J Clin Dermatol. 2013;14 (5):389-399.

46. Agrawal R, Woodfolk JA. Skin barrier defects in atopic dermatitis. Curr Allergy Asthma Rep. 2014;14(5):433. doi:10.1007/s11882-014-0433-9

47. Hon KL, Pong NH, Wang SSS, Lee VW, Luk NM, Leung TF. Acceptability and efficacy of an emollient containing ceramide-precursor lipids and moisturizing factors for atopic dermatitis in pediatric patients. Drugs RD. 2013;13(1):37-42. doi:10.1007/s40268-013-0004-x

48. Hon KL, Leung AKC. Use of ceramides and related products for childhood-onset eczema. Recent Pat Inflamm Allergy Drug Discov. 2012;7(1):12-19.

49. Hon KL, Wang SS, Lau Z, et al. Pseudoceramide for childhood eczema: does it work? Hong Kong Med J. 2011;17(2):132-136.

50. Hon KL, Ching GK, Leung TF, Choi CY, Lee KK, Ng PC. Estimating emollient usage in patients with eczema. Clin Exp Dermatol. 2010;35 (1):22-26. doi:10.1111/j.1365-2230.2009.03341.x

51. vanZuuren EJ, Fedorowicz Z, Arents BWM. Performance and tolerability of the moisturizers Cetaphil((R)) and Excipial((R)) in atopic dermatitis: what is the evidence based on randomized trials? Dermatol Ther. 2017;7(3):331-347. doi:10.1007/s13555-017-0184-3

52. Leung AKC, Barber KA. Managing childhood atopic dermatitis. Adv Ther. 2003;20(3):129-137. doi:10.1007/BF02850199

53. Hon KL, Kam WY, Leung TF, et al. Steroid fears in children with eczema. Acta Paediatr. 2006;95(11):1451-1455. doi:10.1080/ 08035250600612298

54. Hon KL, Tsang YC, Pong NH, et al. Correlations among steroid fear, acceptability, usage frequency, quality of life and disease severity in childhood eczema. J Dermatol Treat. 2015;5:1-8.

55. Fonacier L, Spergel J, Charlesworth EN, et al. Report of the topical calcineurin inhibitor task force of the American college of allergy, asthma and immunology and the American academy of allergy, asthma and immunology. $J$ Allergy Clin Immunol. 2005;115(6):1249-1253. doi:10.1016/j.jaci.2005.04.006

56. Roekevisch E, Spuls PI, Kuester D, Limpens J, Schmitt J. Efficacy and safety of systemic treatments for moderate-tosevere atopic dermatitis: a systematic review. J Allergy Clin Immunol. 2014;133(2):429-438. doi:10.1016/j.jaci.2013. 07.049

57. Meggitt SJ, Reynolds NJ. Azathioprine for atopic dermatitis. Clin Exp Dermatol. 2001;26(5):369-375. doi:10.1046/j.13652230.2001.00837.x

58. Murphy LA, Atherton DJ. Azathioprine as a treatment for severe atopic eczema in children with a partial thiopurine methyl transferase (TPMT) deficiency. Pediatr Dermatol. 2003;20 (6):531-534. doi:10.1111/j.1525-1470.2003.20617.x

59. Hon KL, Chang M, Chong SC, Yuen YP, Tsui SKW. Adverse effects of azathioprine in a child and her mother with eczema. Indian J Pediatr. 2018;85(10):918-919. doi:10.1007/s12098-018-2687-z

60. Wu YL, Zhang H, Yang Y. Cancer drug development in China: recent advances and future challenges. Drug Discov Today. 2015;20(6):766-771.

61. Czarnowicki T, He H, Krueger JG, Guttman-Yassky E. Atopic dermatitis endotypes and implications for targeted therapeutics. J Allergy Clin Immunol. 2019;143(1):1-11. doi:10.1016/j.jaci.2018.10.032

62. Czarnowicki T, Krueger JG, Guttman-Yassky E. Novel concepts of prevention and treatment of atopic dermatitis through barrier and immune manipulations with implications for the atopic march. J Allergy Clin Immunol. 2017;139(6):1723-1734. doi:10.1016/j.jaci.2017.04.004

63. Kalamaha K, Reis E, Newton S, et al. Atopic dermatitis: a review of evolving targeted therapies. Expert Rev Clin Immunol. 2018;1744666X:1560267.
64. Blume-Peytavi U, Bagot M, Tennstedt D, et al. Dermatology today and tomorrow: from symptom control to targeted therapy. J Eur Acad Dermatol Venereol. 2019;33:3-36.

65. Eyerich K, Novak N. Immunology of atopic eczema: overcoming the Th1/Th2 paradigm. Allergy. 2013;68(8):974-982. doi:10.1111/all.12184

66. Lee DE, Clark AK, Tran KA, Shi VY. New and emerging targeted systemic therapies: a new era for atopic dermatitis. $J$ Dermatol Treat. 2018;29:364-374.

67. Tsianakas A, Luger TA. The anti-IL-4 receptor alpha antibody dupilumab: facing a new era in treating atopic dermatitis. Expert. 2015;15(11):1657-1660.

68. Simpson EL, Gadkari A, Worm M, et al. Dupilumab therapy provides clinically meaningful improvement in patient-reported outcomes (PROs): a phase IIb, randomized, placebo-controlled, clinical trial in adult patients with moderate to severe atopic dermatitis (AD). J Am Acad Dermatol. 2016;75(3):506-515. doi:10.1016/j.jaad.2016.04.054

69. Simpson EL, Bieber T, Guttman-Yassky E, et al. Two phase 3 trials of dupilumab versus placebo in atopic dermatitis. $N$ Engl $J$ Med. 2016;375(24):2335-2348. doi:10.1056/NEJMoa1610020

70. Hamilton JD, Ungar B, Guttman-Yassky E. Drug evaluation review: dupilumab in atopic dermatitis. Immunother. 2015;7 (10):1043-1058. doi:10.2217/imt.15.69

71. Simpson EL, Bieber T, Eckert L, et al. Patient burden of moderate to severe atopic dermatitis (AD): insights from a phase $2 \mathrm{~b}$ clinical trial of dupilumab in adults. $J$ Am Acad Dermatol. 2016;74 (3):491-498. doi:10.1016/j.jaad.2015.10.043

72. Thaci D, Simpson EL, Beck LA, et al. Efficacy and safety of dupilumab in adults with moderate-to-severe atopic dermatitis inadequately controlled by topical treatments: a randomised, placebo-controlled, dose-ranging phase $2 \mathrm{~b}$ trial. Lancet. 2016;387(10013):40-52. doi:10.1016/S0140-6736(15)00388-8

73. Mullard A. FDA approves dupilumab for severe eczema. Nat Rev Drug Discov. 2017;16(5):305.

74. Dupilumab (dupixent): an interleukin-4 receptor antagonist for atopic dermatitis - pubmed [internet]. [cited November 30, 2020]. Available from: https://pubmed.ncbi.nlm.nih.gov/ 30186024/. Accessed February 25, 2021.

75. Renert-Yuval Y, Guttman-Yassky E. What's new in atopic dermatitis Dermatol Clin. 2019;37(2):205-213. doi:10.1016/j.det.2018.12.007

76. Fargnoli MC, Esposito M, Ferrucci S. et al. A 48-week update of a multicentre real-life experience of dupilumab in adult patients with moderate-to-severe atopic dermatitis. J Dermatol Treat. 2020:1-4. doi:10.1080/09546634.2020.1773379

77. Patruno C, Napolitano M, Argenziano G, et al. Dupilumab therapy of atopic dermatitis of the elderly: a multicentre, real-life study. J Eur Acad Dermatol Venereol. 2021;jdv:17094. doi: $10.1111 / \mathrm{jdv} .17094$

78. Paller AS, Tom WL, Lebwohl MG, et al. Efficacy and safety of crisaborole ointment, a novel, nonsteroidal phosphodiesterase 4 (PDE4) inhibitor for the topical treatment of atopic dermatitis (AD) in children and adults. J Am Acad Dermatol. 2016;75 (3):494-503. doi:10.1016/j.jaad.2016.05.046

79. Zane LT, Hughes MH, Shakib S. Tolerability of crisaborole ointment for application on sensitive skin areas: a randomized, double-blind, vehicle-controlled study in healthy volunteers. Am J Clin Dermatol. 2016;17(5):519-526. doi:10.1007/s40257-016-0204-6

80. Cheape AC, Murrell DF. 2\% crisaborole topical ointment for the treatment of mild-to-moderate atopic dermatitis. Expert. 2017;13 (5):415-423.

81. Draelos ZD, Stein Gold LF, Murrell DF, Hughes MH, Zane LT. Post hoc analyses of the effect of crisaborole topical ointment, 2\% on atopic dermatitis: associated pruritus from phase 1 and 2 clinical studies. J Drugs Dermatol. 2016;15(2):172-176. 
82. Zane LT, Chanda S, Jarnagin K, Nelson DB, Spelman L, Gold LS. Crisaborole and its potential role in treating atopic dermatitis: overview of early clinical studies. Immunother. 2016;8 (8):853-866. doi:10.2217/imt-2016-0023

83. Tom WL, Van SM, Chanda S, Zane LT. Pharmacokinetic profile, safety, and tolerability of crisaborole topical ointment, $2 \%$ in adolescents with atopic dermatitis: an open-label phase 2a study. Pediatr Dermatol. 2016;33(2):150-159. doi:10.1111/pde.12780

84. Stein Gold LF, Spelman L, Spellman MC, Hughes MH, Zane LT. A phase 2, randomized, controlled, dose-ranging study evaluating crisaborole topical ointment, $0.5 \%$ and $2 \%$ in adolescents with mild to moderate atopic dermatitis. J Drugs Dermatol. 2015;14 (12):1394-1399.

85. Murrell DF, Gebauer K, Spelman L, Zane LT. Crisaborole topical ointment, $2 \%$ in adults with atopic dermatitis: a phase $2 \mathrm{a}$, vehicle-controlled, proof-of-concept study. J Drugs Dermatol. 2015;14(10):1108-1112.

86. Use of topical crisaborole for treating dermatitis in a variety of dermatology settings topical crisaborole for treating dermatitis in dermatology. . Available from: https://www.skintherapyletter. $\mathrm{com} /$ dermatology/topical-crisaborole-dermatitis-treatment/. Accessed February 25, 2021.

87. Huang JT, Abrams M, Tlougan B, Rademaker A, Paller AS. Treatment of Staphylococcus aureus colonization in atopic dermatitis decreases disease severity. Pediatr. 2009;123(5):e808-14.

88. Hon KL, Tsang YC, Lee VW, et al. Efficacy of sodium hypochlorite (bleach) baths to reduce Staphylococcus aureus colonization in childhood onset moderate-to-severe eczema: a randomized, placebo-controlled cross-over trial. J Dermatol Treat. 2016;27(2):156-162.

89. Yanes DA, Mosser-Goldfarb JL. Emerging therapies for atopic dermatitis: the prostaglandin/leukotriene pathway. $\mathrm{J} \mathrm{Am} \mathrm{Acad}$ Dermatol. 2018;78(3):S71-5. doi:10.1016/j.jaad.2017.12.021

90. KaplanSL, ForbesA, HammermanWA, LamberthL, HultenKG, MinardCG, et al. Randomized trial of "bleach baths" plus routine hygienic measures vs. routine hygienic measures alone for prevention of recurrent infections. ClinInfect Dis. 2014;58:679-82.

91. Hon KL, Ng WGG, Kung JSC, Leung PC, Leung TF. Pilot studies on two complementary bath products for atopic dermatitis children: pine-tar and tea. Med (Basel, Switzerland). 2019;6(1):8.

92. Ng WGG, Hon KL, Kung JSC. et al. Effect of pine-tar bath on disease severity in moderate-to-severe childhood eczema: an investigator-blinded, crossover, randomized clinical trial. J Dermatolog Treat. 2020:1-9. doi:10.1080/09546634.2020.1732284

93. Hon KL, Leung AKC, Leung TNH, Lee VWY. Complementary, alternative and integrative medicine for childhood atopic dermatitis. Recent Pat Inflamm Allergy Drug Discov. 2017;11 (2):114-124

94. Hon KLE, Leung TF, Yau HC, Chan T. Paradoxical use of oral and topical steroids in steroid-phobic patients resorting to traditional Chinese medicines. World J Pediatr. 2012;8(3):263-267. doi:10.1007/s12519-012-0369-x

95. Silverberg JI, Lee-Wong M, Silverberg NB. Complementary and alternative medicines and childhood eczema: a US population-based study. Dermatitis. 2014;25(5):246-254. doi:10.1097/DER.0000000000000072

96. Fung AY, Look PC, Chong LY, But PP, Wong E. A controlled trial of traditional Chinese herbal medicine in Chinese patients with recalcitrant atopic dermatitis. Int Dermatol. 1999;38(5):387-392. doi:10.1046/j.1365-4362.1999.00732.x

97. Felding J, Sørensen MD, Poulsen TD, et al. Discovery and early clinical development of 2-\{6-[2-(3,5-dichloro-4- pyridyl)acetyl]-2,3-dimethoxyphenoxy $\}$ - N-propylacetamide (LEO 29102), a soft-drug inhibitor of phosphodiesterase 4 for topical treatment of atopic dermatitis. J Med Chem. 2014;57(14):5893-5903. doi:10.1021/jm500378a
98. Ruzicka T, Hanifin JM, Furue M, et al. Anti-interleukin-31 receptor a antibody for atopic dermatitis. $N$ Engl J Med. 2017;376 (9):826-835. doi:10.1056/NEJMoa1606490

99. Kabashima K, Matsumura T, Komazaki H, Kawashima M, Nemolizumab-JP01 Study Group. Trial of nemolizumab and topical agents for atopic dermatitis with pruritus. $N$ Engl $J$ Med. 2020;383(2):141-150. doi:10.1056/NEJMoa1917006

100. Guttman-Yassky E, Blauvelt A, Eichenfield LF, et al. Efficacy and safety of lebrikizumab, a high-affinity interleukin 13 inhibitor, in adults with moderate to severe atopic dermatitis: a phase $2 b$ randomized clinical trial. JAMA Dermatol. 2020;156 (4):411-420. doi:10.1001/jamadermatol.2020.0079

101. Johnstong BILBAOR, Graham-Brown R. The use of complementary medicine in children with atopic dermatitis in secondary care in Leicester. Br J Dermatol. 2003;149(3):566-571. doi:10.1046/ j.1365-2133.2003.05471.x

102. Schafer T, Riehle A, Wichmann HE, Ring J. Alternative medicine in allergies - prevalence, patterns of use, and costs. Allergy. 2002;57(8):694-700. doi:10.1034/j.1398-9995.2002.23469.x

103. Eichenfield LF, Tom WL, Berger TG, et al. Guidelines of care for the management of atopic dermatitis: section 2. Management and treatment of atopic dermatitis with topical therapies. $J \mathrm{Am}$ Acad Dermatol. 2014;71(1):116-132. doi:10.1016/j. jaad.2014.03.023

104. Hon KL, Luk DC, Leong KF, Leung AK. Cupping therapy may be harmful for eczema: a PubMed search. Case Rep Pediatr. 2013;2013:60582.

105. Salameh F, Perla D, Solomon M, et al. The effectiveness of combined Chinese herbal medicine and acupuncture in the treatment of atopic dermatitis. J Altern Complement Med. 2008;14 (8):1043-1048. doi:10.1089/acm.2008.0162

106. Zhang W, Leonard T, Bath-Hextall F, et al. Chinese herbal medicine for atopic eczema. [Review] [42 refs][update of cochrane database syst rev. 2004;(4):CD002291;PMID: 15495031]. Cochrane Database Syst Rev. 2005;2:CD002291.

107. Shams K, Grindlay DJ, Williams HC. What's new in atopic eczema? An analysis of systematic reviews published in 2009-2010. Clin Exp Dermatol. 2011;36(6):573-577.

108. Gu SX, Zhang AL, Coyle ME, Chen D, Xue CC. Chinese herbal medicine for atopic eczema: an overview of clinical evidence. J Dermatol Treat. 2017;28(3):246-250.

109. Gu S, Yang AW, Xue CC, et al. Chinese herbal medicine for atopic eczema. Cochrane Database Syst Rev. 2013;9: CD008642.

110. Gu S, Yang AW, Li CG, Lu C, Xue CC. Topical application of Chinese herbal medicine for atopic eczema: a systematic review with a meta-analysis. Dermatology. 2014;228(4):294-302. doi:10.1159/000360526

111. Chan BC, Hon KL, Leung PC, et al. Traditional Chinese medicine for atopic eczema: pentaHerbs formula suppresses inflammatory mediators release from mast cells. J Ethnopharmacol. 2008;120 (1):85-91. doi:10.1016/j.jep.2008.07.034

112. Hon KL, Ip M, Wong CK, Chan BC, Leung PC, Leung TF. In vitro antimicrobial effects of a novel Pentaherbs concoction for atopic dermatitis. J Dermatol Treat. 2017;29(3):1-3.

113. Hon KL, Loo S, Leung AKC, Li JTS, Lee VWY. An overview of drug discovery efforts for eczema: why is this itch so difficult to scratch? Expert Opin Drug Discov. 2020;15:487-498. doi:10.1080/ 17460441.2020.1722639

114. Sheehan MP, Rustin MH, Atherton DJ, et al. Efficacy of traditional Chinese herbal therapy in adult atopic dermatitis.[Erratum appears in Lancet 1992 Jul 18;340(8812):188Note: harris DJ [corrected to Harris DW]]. Lancet. 1992;340(8810):13-17. doi:10.1016/0140-6736(92)92424-E

115. Hon KL, Chan BC, Leung PC. Chinese herbal medicine research in eczema treatment. Chinesische Medizin. 2011;6:17. 
116. Sheehan MP, Atherton DJ. A controlled trial of traditional Chinese medicinal plants in widespread non-exudative atopic eczema. $\mathrm{Br} J$ Dermatol. 1992;126(2):179-184. doi:10.1111/ j.1365-2133.1992.tb07817.x

117. Sheehan MP, Atherton DJ. One-year follow up of children treated with Chinese medicinal herbs for atopic eczema. Br J Dermatol. 1994;130(4):488-493. doi:10.1111/j.1365-2133.1994.tb03383.x

118. Sheehan MP, Stevens H, Ostlere LS, Atherton DJ, Brostoff J, Rustin MH. Follow-up of adult patients with atopic eczema treated with Chinese herbal therapy for 1 year. Clin Exp. 1995;20(2):136-140.

119. Hon KL, Leung TF, Wong Y, et al. A pentaherbs capsule as a treatment option for atopic dermatitis in children: an open-labeled case series. Am J Chin Med. 2004;32(6):941-950.

120. Hon KL, Kung JSC, Tsang KYC, Yu JWS, Cheng NS, Leung TF Do we need another symptom score for childhood eczema? 2018:1-5. Available from: https://www.tandfonline.com/doi/full/ 10.1080/09546634.2017.1373734. Accessed February 25, 2021.

121. Kunz B, Oranje AP, Labrèze L, et al. Clinical validation and guidelines for the SCORAD index: consensus report of the European task force on atopic dermatitis. Dermatology. 1997;195(1):10-19. doi:10.1159/000245677

122. Severity scoring of atopic dermatitis: the SCORAD index. Consensus report of the European task force on atopic dermatitis. Dermatology. 1993;186(1):23-31. doi:10.1159/000247298

123. Hon KL, Leung TF, Wong KY, et al. Does age or gender influence quality of life in children with atopic dermatitis? Clin Exp Dermatol. 2008;33(6):705-709. doi:10.1111/j.1365-2230.2008.02853.x

124. Hon KL, Lam MC, Leung TF, et al. CDLQI, SCORAD and NESS: are they correlated? Qual Life Res. 2006;15 (10):1551-1558. doi:10.1007/s11136-006-0019-7

125. Hon KL, Leung TF, Ng PC, et al. Efficacy and tolerability of a Chinese herbal medicine concoction for treatment of atopic dermatitis: a randomized, double-blind, placebo-controlled study. Br J Dermatol. 2007;157(2):357-363. doi:10.1111/j.13652133.2007.07941.x

126. Hon KL, Lee VW, Leung TF, et al. Corticosteroids are not present in a traditional Chinese Medicine formulation for atopic dermatitis in children. Ann Acad Med Singapore. 2006;35 (11):755-759.

127. Hon K, Leung T, Wong $\mathrm{Y}$, et al. A traditional Chinese medicine capsule for atopic dermatitis in children: an open-label trial. $\mathrm{Br}$ J Dermatol. 2004;151(Supple):77.

128. Chang YS, Lin MH, Lee JH, et al. Melatonin supplementation for children with atopic dermatitis and sleep disturbance: a randomized clinical trial. JAMA Pediatr. 2016;170(1):35-42. doi:10.1001/jamapediatrics.2015.3092

129. Boneberger S, Rupec RA, Ruzicka T. Complementary therapy for atopic dermatitis and other allergic skin diseases: facts and controversies.. Clin Dermatol. 2010;28(1):57-61. doi:10.1016/j. clindermatol.2009.03.017

130. Chen CJ, Yu HS. Acupuncture, electrostimulation, and reflex therapy in dermatology. Dermatol Ther. 2003;16(2):87-92.

131. Hon KL, Leung TF, Tse HM, et al. A survey of attitudes to traditional Chinese medicine among Chinese medical students. Am J Chin Med. 2005;33(2):269-279.

132. Marseglia A, Licari A, Agostinis F, et al. Local rhamnosoft, ceramides and L-isoleucine in atopic eczema: a randomized, placebo controlled trial. Pediatr Allergy Immunol. 2014;25 (3):271-275. doi:10.1111/pai.12185

133. Zhang S, Zeng X, Wei J, Li S, He S. Analysis of trends and opportunities of anti-allergy patents in China from 1998 to 2008. Recent Pat Inflamm Allergy Drug Discov. 2010;4(2):130-137. doi:10.2174/187221310791163116

134. Hon KL, Leung AK. Powerful proprietary Chinese medicine for eczema? Clin Exp Dermatol. 2010;35(3):e14-e15. doi:10.1111/ j.1365-2230.2009.03287.x
135. Smith SH, Jayawickreme C, Rickard DJ, et al. Tapinarof is a natural ahr agonist that resolves skin inflammation in mice and humans. $J$ Invest Dermatol. 2017;137(10):2110-2119. doi:10.1016/j.jid.2017.05.004

136. Paller AS, Gold LS, Soung J, Tallman AM, Rubenstein DS, Gooderham M. Efficacy and patient-reported outcomes from a Phase IIb, randomized clinical trial of tapinarof cream for the treatment of adolescents and adults with atopic dermatitis. $J \mathrm{Am}$ Acad Dermatol. 2020. Available from: https://pubmed.ncbi.nlm. nih.gov/32502588/. Accessed February 25, 2021.

137. Papp KA, Gooderham M, Droege M, et al. Roflumilast cream improves signs and symptoms of plaque psoriasis: results from a phase 1/2a Randomized, Controlled Study. J Drugs Dermatol. 2020;19(8):734-740. doi:10.36849/JDD.2020.5370

138. Lebwohl MG, Papp KA, Gold LS, et al. Trial of roflumilast cream for chronic plaque psoriasis. $N$ Engl J Med. 2020;383 (3):229-239. doi:10.1056/NEJMoa2000073

139. Agnihotri G, Lio PA. Revisiting therapies for atopic dermatitis that failed clinical trials. Clin Drug Investig. 2020;40(5):421-431. doi:10.1007/s40261-020-00905-7

140. Korenblat P, Kerwin E, Leshchenko I, et al. Efficacy and safety of lebrikizumab in adult patients with mild-to-moderate asthma not receiving inhaled corticosteroids. Respir Med. 2018;134:143-149. doi:10.1016/j.rmed.2017.12.006

141. Hanania NA, Korenblat P, Chapman KR, et al. Efficacy and safety of lebrikizumab in patients with uncontrolled asthma (LAVOLTA I and LAVOLTA II): replicate, phase 3, randomised, double-blind, placebo-controlled trials. Lancet Respir Med. 2016;4(10):781-796. doi:10.1016/S2213-2600(16)30265-X

142. Hanania NA, Noonan M, Corren J, et al. Lebrikizumab in moderate-to-severe asthma: pooled data from two randomised placebo-controlled studies. Thorax. 2015;70(8):748-756. doi:10.1136/thoraxjnl-2014-206719

143. Simpson EL, Flohr C, Eichenfield LF, et al. Efficacy and safety of lebrikizumab (an anti-IL-13 monoclonal antibody) in adults with moderate-to-severe atopic dermatitis inadequately controlled by topical corticosteroids: a randomized, placebo-controlled phase II trial (TREBLE). J Am Acad Dermatol. 2018;78(5):863-871.e11. doi:10.1016/j.jaad.2018.01.017

144. Silverberg JI, Lei D, Yousaf M, et al. What are the best endpoints for eczema area and severity index and scoring atopic dermatitis in clinical practice? A prospective observational study. $\mathrm{Br}$ J Dermatol. 2020. doi:10.1111/bjd.19457

145. Morra DE, Drucker AM. Tralokinumab for atopic dermatitis: a promising new therapy. Br J Dermatol. 2020. doi:10.1111/bjd.19699

146. Silverberg JI, Guttman-Yassky E, Gooderham M, et al. Healthrelated quality of life with tralokinumab in moderate-to-severe atopic dermatitis A phase $2 \mathrm{~b}$ randomized study. Ann Allergy Asthma Immunol. 2020. doi:10.1016/j.anai.2020.12.004

147. Mobasher P, Heydari SM, Raffi J, Juhasz M, Atanaskova MN. Oral small molecules for the treatment of atopic dermatitis: a systematic review. J Dermatolog Treat. 2018;1-8. Available from: http://www. ncbi.nlm.nih.gov/pubmed/30501539. Accessed February 25, 2021.

148. Cotter DG, Schairer D, Eichenfield L. Emerging therapies for atopic dermatitis: JAK inhibitors. J Am Acad Dermatol. 2018;78 (3):S53-S62. doi:10.1016/j.jaad.2017.12.019

149. Guttman-Yassky E, Silverberg JI, Nemoto O, et al. Baricitinib in adult patients with moderate-to-severe atopic dermatitis: a phase 2 parallel, double-blinded, randomized placebo-controlled multiple-dose study. J Am Acad Dermatol. 2019;80(4):913-921. e9. doi:10.1016/j.jaad.2018.01.018

150. Simpson EL, Sinclair R, Forman S, et al. Efficacy and safety of abrocitinib in adults and adolescents with moderate-to-severe atopic dermatitis (JADE MONO-1): a multicentre, double-blind, randomised, placebo-controlled, phase 3 trial. Lancet. 2020;396 (10246):255-266. doi:10.1016/S0140-6736(20)30732-7 
151. Gooderham MJ, Forman SB, Bissonnette R, et al. Efficacy and safety of oral janus kinase 1 inhibitor abrocitinib for patients with atopic dermatitis: a phase 2 randomized clinical trial. JAMA Dermatol. 2019;155(12):1371-1379. doi:10.1001/jamadermatol.2019.2855

152. Oprita R, Bratu M, Oprita B, Diaconescu B. Fecal transplantation - the new, inexpensive, safe, and rapidly effective approach in the treatment of gastrointestinal tract diseases. J Med Life; 9:160-2.

153. Guttman-Yassky E, Brunner PM, Neumann AU, et al. Efficacy and safety of fezakinumab (an IL-22 monoclonal antibody) in adults with moderate-to-severe atopic dermatitis inadequately controlled by conventional treatments: a randomized, double-blind, phase 2a trial. J Am Acad Dermatol. 2018;78 (5):872-881.e6. doi:10.1016/j.jaad.2018.01.016

154. Bonchak JG, Swerlick RA. Emerging therapies for atopic dermatitis: TRPV1 antagonists. J Am Acad Dermatol. 2018;78(3):S63S66. doi:10.1016/j.jaad.2017.12.023

155. Gueniche A, Knaudt B, Schuck E, Volz T, Bastien P, Martin R, et al. Effects of nonpathogenic gram-negative bacterium. Vitreoscilla filiformis. lysate on atopic dermatitis: a prospective, randomized, double-blind, placebo-controlled clinical study. $\mathrm{Br} \mathrm{J}$ Dermatol. $2008 ; 159: 1357-63$.

156. Jain A, Agarwal A. Biofilm production, a marker of pathogenic potential of colonizing and commensal staphylococci. J Microbiol Methods. 2009;76:88-92.

157. Kuo I-H, Carpenter-Mendini A, Yoshida T, McGirt LY, Ivanov AI, Barnes KC, et al. Activation of epidermal toll-like receptor 2 enhances tight junction function: implications for atopic dermatitis and skin barrier repair. J Invest Dermatol. 2013;133:988-98.
158. MylesI A, Williams KW, Reckhow JD, Jammeh ML, Pincus NB, SastallaI, et al. Transplantation of human skin microbiota in models of atopic dermatitis. JCI insight. 2016;1.

159. Nakatsuji T, Chen TH, Narala S, Chun KA, Two AM, Yun T, et al. Antimicrobials from human skin commensal bacteria protect against Staphylococcus aureus and are deficient in atopic dermatitis. Sci Transl Med. 2017;9(378).

160. MylesI A, Earland NJ, Anderson ED, Moore IN, Kieh MD, WilliamsKW, et al. First-in-human topical microbiome transplantation with Roseomonas mucosa for atopic dermatitis. JCI Insight. 2018;3(9).

161. Paller AS, Kabashima K, Bieber T. Therapeutic pipeline for atopic dermatitis: End of the drought?. J Allergy Clin Immunol. 2017;140:633-43.

162. Chen YL, Gutowska-Owsiak D, Hardman CS, et al. Proof-ofconcept clinical trial of etokimab shows a key role for IL-33 in atopic dermatitis pathogenesis. Sci Transl Med. 2019;11(515): eaax2945.

163. Simpson EL, Parnes JR, She D, Crouch S, Rees W, Mo M, et al. Tezepelumab, an anti-thymic stromal lymphopoietin monoclonal antibody, in the treatment of moderate to severe atopic dermatitis: A randomized phase 2a clinical trial. J Am Acad Dermatol. 2019;80:1013-21.

\section{Publish your work in this journal}

The Journal of Experimental Pharmacology is an international, peerreviewed, open access journal publishing original research, reports, reviews and commentaries on all areas of laboratory and experimental pharmacology. The manuscript management system is completely online and includes a very quick and fair peer-review system. Visit http://www.dovepress.com/testimonials.php to read real quotes from published authors. 